\title{
A Comparison between Anti-Thyroid Antibody Positive Euthyroid and Anti-Thyroid Antibody Negative Euthyroid in Pregnancy: A Study in a Tertiary Care Hospital, Dhaka, Bangladesh
}

\author{
Md. Jahangir Alam ${ }^{*}$, Md. Fariduddin' ${ }^{2}$, M. A. Hasanat ${ }^{2}$, Murshed Ahamed Khan ${ }^{3}$, M. A. Shehab ${ }^{4}$
}

${ }^{1}$ Assistant Professor (Endocrinology), Shaheed Ziaur Rahman Medical College, Bogura, Bangladesh

${ }^{2}$ Professor (Endocrinology), Bangabandhu Sheikh Mujib Medical University (BSMMU), Shahbag Dhaka, Bangladesh

${ }^{3}$ Assistant Professor (Endocrinology), Bangabandhu Sheikh Mujib Medical University (BSMMU), Shahbag, Dhaka, Bangladesh

${ }^{4}$ Medical Officer, Shaheed Ziaur Rahman Medical College Hospital, Bogura, Bangladesh

DOI: $10.36347 /$ sjams.2020.v08i09.040

| Received: 14.03.2020 | Accepted: 21.03.2020 | Published: 28.09.2020

*Corresponding author: Dr. Md. Jahangir Alam

\section{Abstract}

Original Research Article

Introduction: Thyroid disorders in pregnancy are receiving attention from many scientific corners. Over the past several years it has been proved that maternal thyroid disorders influence the outcome of mother and fetus during and also after pregnancy. Material \& Methods: This observational and longitudinal study encompassed 300 pregnant mothers who were recruited on consecutive basis in their first trimester from the department of Obstetrics and Gynecology. BSMMU and antenatal clinic of a maternity hospital after fulfillment of inclusion criteria. Assay for antithyroid peroxidase (anti-TPO) and anti-thyroglobulin (anti-TG) antibodies as well as free thyroxin (FT4) and thyroid stimulating hormone (TSH) were done by automated chemiluminescent method. Study subjects were categorized into normal and disorder groups on the basis of American thyroid association (ATA) defined criteria and all pregnant women were followed throughout the pregnancy till delivery, to note any adverse feto-maternal outcome. Results: Mean maternal age $( \pm \mathrm{SD})$ was $25.68 \pm 4.50$ years. Median gestational age on recruitment in the first trimester was 11.0 weeks. Most of the mothers were housewife $(74.0 \%)$ followed by service holder $(19.3 \%)$ and students $(6.7 \%)$. About one third mother $(29 \%)$ had history of previous abortion; $37 \%$ were primigravida and $46 \%$ were nulliparous indicating abortion or miscarriage in some mothers. Out of 300 pregnant mothers more than 200 were negative for both antibodies, 28 were positive for both antibodies, while 50 were positive for only anti-TPO and 12 were positive for only anti-TG $(p<0.001$, by McNemar's test). These frequencies for euthyroid $(n=19): 6,8,4$ and 1 ( $p=0.375)$, for hypothyroid $(n=7): 2,0,4$ and $1(p=0.375)$, for $\mathrm{SCH}(n=102): 69,10,18$ and $5(\mathrm{p}=0.011)$ and for subclinical hyper $(n=9): 5,2,2$ and $0(p=0.500)$ respectively. When antibody status was considered combined 90 subjects were positive and 210 were negative. Frequencies of positive and negative antithyroid antibodies status among various subclasses were found to be disturbed differently. Hypertension-preeclampsia was found in 24 , spontaneous abortion 24 , placental abruption 2, Caesarean section in the dysfunction group (euthyroid vs. dysfunction: hypertensionpreeclampsia $45.8 \%$ vs. $54.2 \%, p=0.505$, placental abruption $0 \%$ vs. $100 \%, p=0.137$, Caesarean section $48.6 \%$ vs. 51.4\%, $\mathrm{p}=0.094)$. Conclusion: Maternal and fetal complications may be reduced if treatment is given when dysfunction is detected earlier in pregnancy.

Keywords: Anti-thyroid, Antibody positive euthyroid, Pregnancy.

Copyright @ 2020: This is an open-access article distributed under the terms of the Creative Commons Attribution license which permits unrestricted use, distribution, and reproduction in any medium for non-commercial use (NonCommercial, or CC-BY-NC) provided the original author and source are credited.

\section{INTRODUCTION}

The prevalence of autoimmune thyroid disorders (AITD) is quite high in Bangladesh and thyroid autoimmunity is higher in pregnant women with a history of recurrent abortion compared with the healthy pregnant control population $[1,2]$. In total $10 \%$ $20 \%$ of all pregnant women in the first trimester of pregnancy are thyroid peroxidase (TPO) or thyroglobulin (Tg) antibody positive and euthyroid [3]. Anti thyroid antibodies may be positive in a limited percentage of healthy controls and in about $11 \%$ of nonautoimmune thyroid disease (NAITD). High iodine intake as well as widely varying concentration of day to day dietary iodine increases vulnerability to development of thyroid autoimmunity [2]. TSH levels have been found higher (within the normal range) in euthyroid women who are positive for TPO or $\mathrm{Tg}$ antibodies than in those women without it and in some studies women with thyroid antibodies are older than those without antibodies. Women who are euthyroid but 
carry thyroid antibodies at the onset of pregnancy have an increased risk for progression of hypothyroidism during gestation [4], There may be justification for proposing a systematic screening for antibodies in early month of pregnancy for following rationale I) increased risk of spontaneous miscarriage II) risk of progressive hypothyroidism, III) risk of postpartum thyroiditis after pregnancy and, IV) family the well-known long term risk of developing definitive hypothyroidism later on in life [5]. Recently one study in Endocrinology department of BSMMU shows that $17.5 \%$ pregnant women (total $\mathrm{n}=200$ ) are positive for thyroid autoantibodies [6]. Hence all pregnant women with auto immune thyroid disease (AITD) should be monitored closely throughout the gestation. Maternal complications are significantly higher in most of the patients with overt hypothyroidism and they have an increased prevalence of abortion, hypertension/preeclampsia, placental abruption and postpartum hemorrhage. Gestational hyperthyroidism is typically associated with hyperemesis gravidarum and other maternal adverse outcome is preeclampsia [4] Thyroid autoantibodies during pregnancy are also associated with increased risk of spontaneous miscarriage [5]. On the other hand, sub clinical hyperthyroidism is not associated with adverse pregnancy outcomes [7]. Another study also revealed that the urinary iodine concentration in euthyroid pregnant women is markedly lower than those previously reported in our country. Considering this Iodine status in pregnancy, autoimmunity and adverse effects of thyroid dysfunction during pregnancy, patients with thyroid disorders should be assessed and treated depending on severity. Poorly controlled disease during pregnancy can cause serious complications for both mother and fetus. Sufficient data on pregnancy outcome in patients with thyroid disorders are lacking in our country. The aim of this study was to compare between anti-thyroid antibody positive euthyroid and anti-thyroid antibody negative euthyroid in pregnancy.

\section{OBJECTIVES}

\section{General objective}

- To observe frequency of maternal and fetal complications in cuthuld and thyroid dysfunction groups

\section{Specific Objectives}

- To evaluate the frequency of thyroid dysfunction in early pregnancy

- To compare the frequencies of complications in euthyroid and treated dysfunctional groups.

- To compare the frequencies of complications in antibody positive and antibody negative groups with thyroid dysfunction

\section{Methodology and Materials}

This was a cohort study which was carried out during the period from December 2012 to June 2014 at the Department of Endocrinology, BSMMU, Dhaka, Bangladesh. This observational and longitudinal study encompassed 300 pregnant mothers who were recruited on consecutive basis in their first trimester from the Department of Obstetrics and Gynecology, BSMMU and antenatal clinic of a maternity hospital after fulfillment of inclusion criteria. Assay for anti-thyroid peroxidase (anti-TPO) and anti-thyroglobulin (anti-TG) antibodies as well as free thyroxin (FT4) and thyroid stimulating hormone (TSH) were done by automated chemiluminescent method. Study subjects were categorized into normal and disorder groups on the basis of American Thyroid Association (ATA) defined criteria and all pregnant women were followed throughout the pregnancy till delivery, to note any adverse feto-maternal outcome.

\section{Inclusion Criteria}

- Pregnant women with biochemically proved thyroid dysfunction in the 1 st trimester (normal function considered as control).

- Female, aged 20 to 35 years.

- Mothers not taking any thyroxine supplement.

\section{Exclusion Criteria}

- Patients with already known thyroid disease.

- Patients with other co-morbid disease assessed clinically or biochemically

- Pregnant women not willing to participate or give consent.

\section{RESULTS}

Characteristics of the participants are shown in Table-1 where we see mean maternal age $( \pm S D)$ was $25.68 \pm 4.50$ years. Median gestational age on recruitment in the first trimester was 11.0 weeks. Most of the mothers were housewife $(74.0 \%)$ followed by service holder $(19.3 \%)$ and students $(6.7 \%)$. About one third mother $(29 \%)$ had history of previous abortion; $37 \%$ were primigravida and $46 \%$ were nulliparous indicating abortion or miscarriage in some mothers. There was no goiter in $47 \%$ mothers whereas $43 \%$ had grade I and $10 \%$ had grade II goiter (Fig-1). As shown in Table-2 and Fig-2 according to ATA criteria more than half of the mothers $(54.3 \%)$ fell into euthyroid group followed by subclinical hypothyroid (34\%), overt hypothyroid, (6.3\%), subclinical hyperthyroid (3.0\%), clinical hyperthyroid (2.6\%). As observed (Table-3 and Fig-3), most mothers having thyroid dysfunction of any form had associated goiter (OH:78.9\%, SCH:56.9\%, subclinical hyperthyroidism: $66.7 \%$, hyperthyroidism: $71.4 \%$ ) while it was $46 \%$ in mothers iin normal thyroid function $\left(\square^{2}=10.571, \mathrm{p}=0.032\right.$. Table-5 and Fig-4 depicits the frequencies of positive and negative status of antithyroid antibodies among the ATA defined functional classes. Out of 300 pregnant mothers more than 200 were negative for both antibodies, 28 were positive for both antibodies, while 50 were positive for only anti-TPO and 12 were positive for only anti-TG 
( $\mathrm{p}<0.001$, by McNemar's test). These frequencies for euthyroid $(n=19): 6,8,4$ and $1 \quad(p=0.375)$, for hypothyroid $(n=7): 2,0,4$ and $1(p=0.375)$, for $\mathrm{SCH}$ $(\mathrm{n}=102): 69,10,18$ and $5(\mathrm{p}=0.011)$ and for subclinical hyper $(\mathrm{n}=9): 5,2,2$ and $0(\mathrm{p}=0.500)$ respectively. When antibody status was considered combined (Table-6, Fig5) 90 subjects were positive and 210 were negative. Frequencies of positive and negative antithyroid antibodies status among various subclasses were found to be disturbed differently. $\mathrm{OH}(68.4 \%)$, Overt hyper $(71.4 \%)$ and Subclinical hyper $(44.4 \%)$ were found to be more positive for antithyroid antibodies than that for euthyroid (1.5\%) ad SCH (32.4\%) subclasses of subjects which were statistically different $\left(\square^{2}=25.885\right.$, $\mathrm{p}<0.001$. Fig-5 shows the frequency of abortion in the context of antithyroid antibody status. There was no statistically significant difference for the frequency of abortion between the positive and negative status of antithyroid antibody $\left(\square^{2}=0.039, \mathrm{p}=0.843\right)$. Also, the frequency of abortion in both positive (9.8\%) and negative $(8.4 \%)$ subjects were lesss than $10 \%$. Frequency of maternal complications during and after pregnancy is displayed in Table-7. Hypertensionpreeclampsia was found in 24 , spontaneous abortion 24 , placental abruption 2, Caesarean section in the dysfunction group (euthyroid vs. dysfunction: hypertension-preeclampsia $45.8 \%$ vs. $54.2 \%, p=0.505$, placental abruption $0 \%$ vs. $100 \%, \mathrm{p}=0.137$, Caesarean section $48.6 \%$ vs. $51.4 \%, \mathrm{p}=0.094)$. As shown in Table-IX frequency of Caesarean section was the most frequent complication in all subjects of $\mathrm{SCH}, \mathrm{OH}$, subclinical hyperthyroidism and clinical hyperthyroidism $(71.1 \%, 61.1 \%, 57.1 \%, 85.7 \%, 12.5 \%$ and $28.6 \%$ respectively) followed by hypertensionpreeclampsia $(8.1 \%, 10.5 \%$ respectively), Spontaneous abortion $(7.1 \%, 21.1 \%, 25.0 \%$ and $0 \%$ respectively).

Table-1: Characteristics of the studied pregnant women $(\mathrm{N}=300)$

\begin{tabular}{|l|l|}
\hline Characteristics & Value \\
\hline Numbers & $\mathbf{3 0 0}$ \\
\hline Maternal age (Yrs. M+SD) & $25.64 \pm 4.504$ \\
\hline Profession & $222(74.0 \%)$ \\
\hline Housewife & $58(19.3 \%)$ \\
\hline Service & $20(6.7 \%)$ \\
\hline Students & 11 \\
\hline Median gestetional age (wks.) \\
\hline Gravita & $110(36.7 \%)$ \\
\hline 1 & $96(32.0 \%)$ \\
\hline 2 & $94(31.3 \%)$ \\
\hline$\geq 3$ & $138(46 \%)$ \\
\hline Parity & $105(35 \%)$ \\
\hline o & $42(14 \%)$ \\
\hline 1 & $15(5 \%)$ \\
\hline 2 & $141(47 \%)$ \\
\hline$\geq 3$ & $129(43 \%)$ \\
\hline History of previous abortion & $129(43 \%)$ \\
\hline Thyromegaly & $30(10 \%)$ \\
\hline Grade 0 & \\
\hline Grade1 & \\
\hline Grade2 & \\
\hline
\end{tabular}

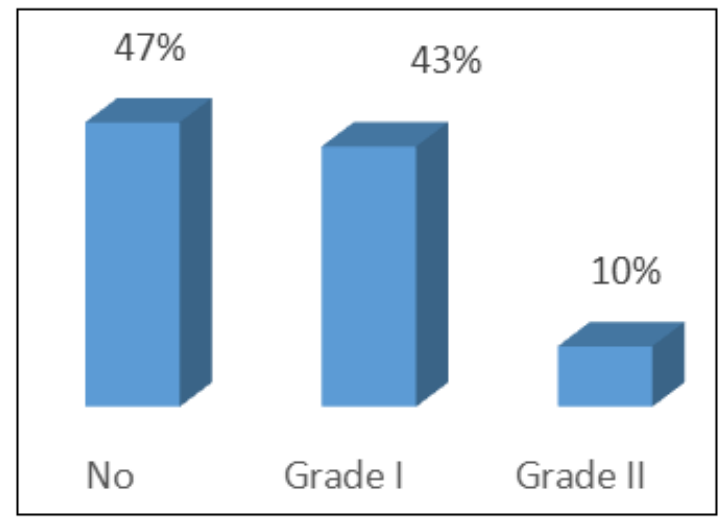

Fig-1: Frequency of various grades of goiter $(\mathrm{N}=300)$ 
Table-2: ATA defined thyroid function in studied pregnant women. ( $N=300$ )

\begin{tabular}{|l|l|l|}
\hline Parameter & $\mathbf{n}$ & $\mathbf{\%}$ \\
\hline Euthyroid & 163 & 54.3 \\
\hline Overt Hypothyroidism & 19 & 6.3 \\
\hline Subclinical Hypothyroidism & 102 & 34 \\
\hline Overt Hyperthyroidism & 7 & 2.3 \\
\hline Subclincal Hyperthyroidism & 9 & 3 \\
\hline Total & 300 & 100 \\
\hline
\end{tabular}

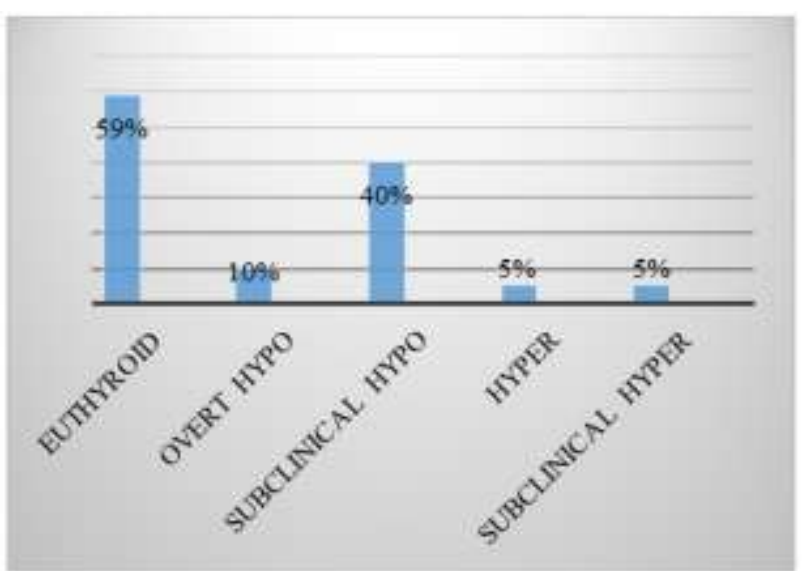

Fig-2: Functional Categories of the subjects $(\mathrm{N}=300)$

Table-3: Relationship between ATA defined functional status and goiter $(\mathbf{N}=300)$

\begin{tabular}{|l|l|l|l|l|l|l|l|}
\hline \multirow{2}{*}{ Goiter Status } & \multicolumn{4}{|l|}{ ATA defined functionl groups } & $\square^{2}, \mathbf{p}$ \\
\cline { 2 - 7 } & Euthyroid & Overt Hypo & Overt hyper & Subcl. Hypo & Subcl. Hyper & Total & $\square^{2}=10.571 \mathrm{p}=0.032$ \\
\hline Goiter & $75(46.0)$ & $15(78.9)$ & $05(71.4)$ & $58(56.9)$ & $6(66.7)$ & $159(53)$ & \\
& No Goiter & $88(54.0)$ & $04(21.1)$ & $02(28.6)$ & $44(43.1)$ & $03(33.3)$ & $141(47)$ \\
\hline Total & 163 & 19 & 7 & 102 & 9 & 300 & \\
\hline
\end{tabular}

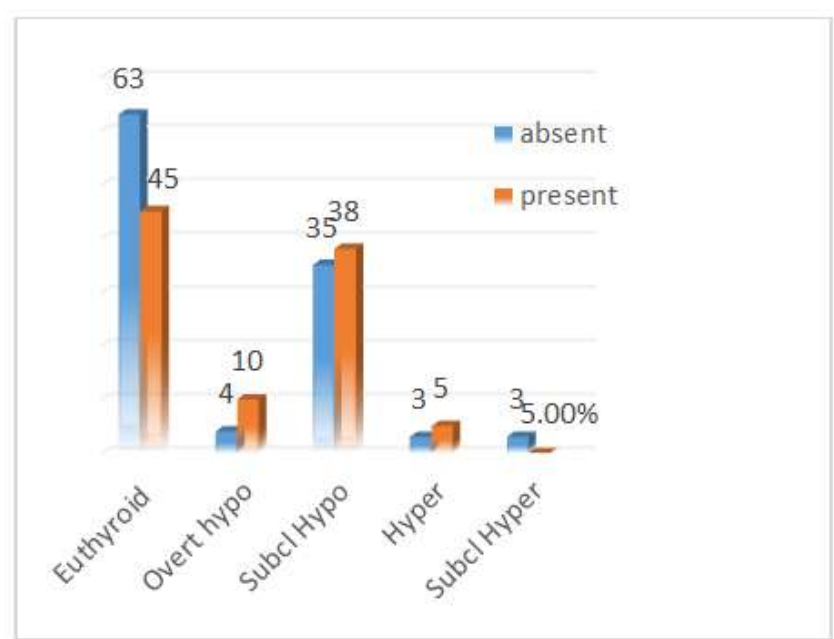

Fig-3: Frequency of goiter among the functional groups

Table-4: Anti-thyroid antibody status among the studied subjects $(n=300)$

\begin{tabular}{|l|l|l|l|l|l|l|}
\hline \multirow{2}{*}{ Antibody Status } & \multicolumn{2}{|l|}{ ATA defined functional groups } & Total \\
\cline { 2 - 8 } & Euthyroid & Hypo thyroid & Hyper thyroid & Subclin. Hypo & Subclin Hyper & \\
\hline Only anti-TPO ab positive & 22 & 4 & 4 & 18 & 2 & 50 \\
\hline Onli anti-TG ab positive & 5 & 1 & 1 & 5 & 0 & 12 \\
\hline Both anti-TPO and anti-TG positive & 8 & 8 & 0 & 10 & 2 & 28 \\
\hline Both anti-TPO and anti-TG negative & 128 & 6 & 2 & 69 & 5 & \\
\hline Total & 163 & 19 & 7 & 102 & 9 & 210 \\
\hline P value & 0.002 & 0.375 & 0.375 & 0.011 & 0.5 & 300 \\
\hline
\end{tabular}




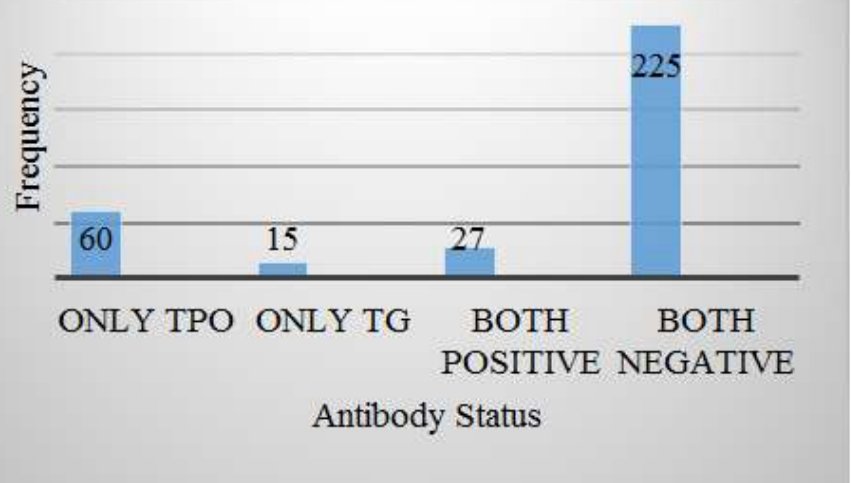

Fig-4: Status of anti-thyroid antibody the functional groups

Table-5: Antibody status among ATA defined functional groups $(n=300)$

\begin{tabular}{|l|l|l|l|l|}
\hline \multirow{2}{*}{ Functional Status } & \multicolumn{2}{|c|}{ Antibody Status } & \multirow{2}{*}{ Total } & $\square^{2}$ and p \\
\cline { 2 - 3 } & Positive (\%) & Negative (\%) & & \\
\hline Euthyroid & $35(21.5)$ & $128(78.5)$ & 163 & \multirow{2}{*}{$\square^{2}=25.885, \mathrm{p}<0.001$} \\
\hline Overt Hypothyroidism & $13(68.4)$ & $6(31.6)$ & 19 & \\
\hline Subclinical Hypothyroidism & $33(32.4)$ & $69(67.6)$ & 102 & \\
\hline Overt Hyperthyroidism & $5(71.4)$ & $2(28.6)$ & 7 & \\
\hline Subclinical Hyperthyroidism & $4(44.4)$ & $5(55.6)$ & 9 & \\
\hline Total & 90 & 210 & 300 & \\
\hline
\end{tabular}

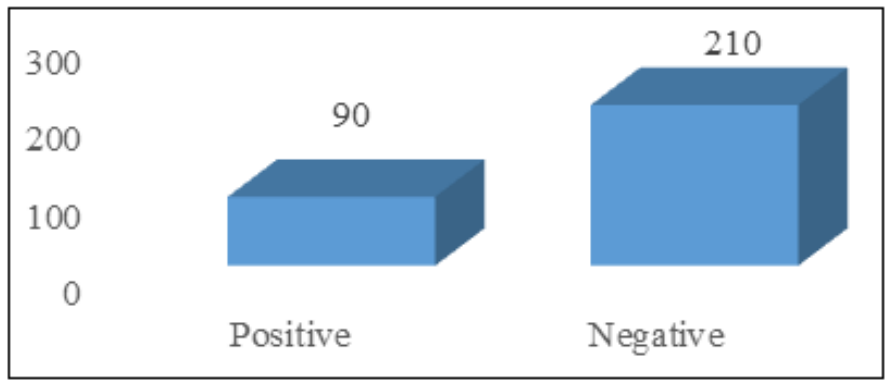

Fig-5: Frequency of abortion and its relevance to antibody status.

Table-6: Maternal complications in euthyroid and thyroid dysfunction pantients

\begin{tabular}{|l|l|l|l|l|l|}
\hline Complications & Euthyroid & Dysfunction & Total & $\square^{\mathbf{2}}$ & P \\
\hline Hypertention/Preeclampsia & $11(45.8)$ & $13(54.2)$ & 24 & 0.444 & 0.505 \\
\hline Spontaneous abortion & $11(45.8)$ & $13(54.2)$ & 24 & 0.444 & 0.505 \\
\hline Placental abruption & $0(0)$ & $2(100)$ & 2 & 2.211 & 0.137 \\
\hline Caesarean section & $90(48.6)$ & $95(51.4)$ & 185 & 2.809 & 0.094 \\
\hline Postpartum haemorrhage & $0(0)$ & $0(0)$ & 0 & - & - \\
\hline
\end{tabular}

Table-7: Frequency of maternal complications in functional subgroups

\begin{tabular}{|l|l|l|l|l|}
\hline Complications & $\begin{array}{l}\text { Subclinical hypo } \\
(\mathbf{n = 9 6 - 9 9 )}\end{array}$ & $\begin{array}{l}\text { Overt hypo } \\
(\mathbf{n = 1 8 - 1 9 )}\end{array}$ & $\begin{array}{l}\text { Subclinial } \\
\text { hyper }(\mathbf{n = 7 - 8})\end{array}$ & $\begin{array}{l}\text { Cilinical } \\
\text { hyper }(\mathbf{n}=7)\end{array}$ \\
\hline Hypertention/Preeclampsia & $08(8.1)$ & $02(10.5)$ & $0.1(12.5)$ & $02(28.6)$ \\
\hline Spontaneous abortion & $07(7.10)$ & $04(21.1)$ & $02(25.0)$ & $00(0.0)$ \\
\hline Placental abruption & $02(2.0)$ & $00(0.0)$ & $00(0.0)$ & $00(0.0)$ \\
\hline Caesarean section & $74(77.1)$ & $11(61.1)$ & $04(57.1)$ & $0.6(85.7)$ \\
\hline
\end{tabular}

\section{DisCUSSION}

This study was performed to detect the adverse pregnancy outcome in patients with thyroid disorders according to trimester specific reference range defined by ATA, who has no history of detectable thyroid abnormality or risk factors prior to pregnancy According to ATA defined TSH level, out of 300 studied subject $163(54.3 \%)$ were euthyroid, 102(34\%) subclinical hypothyroid, $19(6.3 \%)$ overt hypothyroid, 9 (3\%) subclinical hyperthyroid and $7(2.3 \%)$ clinical 
hyperthyroid. Similar study conducted by Begum et al., [8] in BSMMU using the conventional non-pregnant reference range for TSH in 200 pregnant women (up to 20 wks of gestation) showed subclinical hypothyroid $5 \%$, overt hypothyroid $3 \%$, subclinical hyperthyroid $4 \%$ and overt hyperthyroid $3.5 \%$. Another study by Shah et al., [9] in India involving 2000 pregnant women attending antenatal clinic using the conventional nonpregnant TSH reference range shows, 94\% were euthyroid, $3.5 \%$ had subclinical hypothyroidism, had overt hypothyroidism and $0.6 \%$ had overt hyperthyroidism. Being an iodine deficient area like us the percentage of subclinical and clinical hyperthyroidism (3\% and $2.3 \%$ respectively) might have been higher and in one study [10] the cause of high incidence was explained by transient gestational hyperthyroidism in the first trimester of pregnancy. Analysis of antibody status in the studied subjects revealed no significant difference for individual antibody (anti-TPO and anti-TG) in any of the ATA defined functional group. Considering status of both the antibodies for positivity or negativity among the subjects, it was found that overt hyperthyroidism $(71.4 \%)$ had the highest frequency for positive antibody status followed by overt hypothyroidism $(68.4 \%)$. Also, euthyroid subjects showed $21.5 \%$ positivity. Hasanat et al., [2] had studied status of antithyroid antibody in Bangladesh among male and nonpregnant female and observed higher frequency of autoimmune thyroid disease $(48.36 \%)$ with antibody positivity in Hashimotos thyroiditis $(63.0 \%)$, atrophic thyroiditis $(44.7 \%)$ and Graves' disease (36.4\%). Others have observed prevalence of hyperthyroidism significantly higher in anti TPO antibody positive pregnant women than anti-TPO antibody positive pregnant women than anti-TPO antibody negative pregnant women [11]. These findings were consistent with this study. Prevalence of subclinical hypothyroidism among pregnant women was found fairly high among Indians and they have high rates of TPO antibody positivity [11]. This study supports similar findings in Bangladeshi pregnant women. Antibody positivity (21.5\%) among euthyroid subject in this study is also consistent with data from the third National Health and Nutrition Examination Survey (NHANES-III), where anti-TPO positivity and anti-TG antibody positivity was found in $12.6 \%$ and $13.6 \%$ of euthyroid women respectively. ${ }^{12}$ Women in euthyroid state but with thyroid autoimmunity are twice likely to experience spontaneous miscarriage as it probably represents a generalized activation of immune system or there is an increased risk of progression to subclinical hypothyroidism or probably due to transplacental transfer of thyroid receptor blocking antibodies [1, 13, 14]. In this context, Mannisto et al., [15] describes that both anti-TPO antibody and anti-TG antibodies are independent risk factors for subsequent thyroid disease. In observing frequency of maternal complications during and after pregnancy, hypertension-preeclampsia was found in 24 , spontaneous abortion 24. placental abruption 2, Caesarean section 185 and PPH in none among the studied mothers. When compared between euthyroid and dysfunction groups, these complications were not statistically different except a higher frequency for Caesarean section in the dysfunction group (euthyroid vs. dysfunction: hypertension-preeclampsia $45.8 \%$ vs. $54.2 \%, \mathrm{p}=0.505$, spontaneous abortion $45.8 \%$ vs. $54.3 \%, \mathrm{p}=0.505$, placental abruption $0 \%$ vs. $100 \%$, $\mathrm{p}=0.137$, Caesarean section $48.6 \%$ vs. $51.4 \%$, $\mathrm{p}=0.094$ ). Higher frequency for Caesarean section may be attributed to the fact that electively mothers with thyroid dysfunction might have preferred Caesarean section. Our study also observed the fetal complications in euthyroid and dysfunction group. None of preterm delivery $(16.3 \%$, vs. $49.3 \%, \mathrm{p}=0.528)$, LBW (14.3\% vs. $16.5 \%, \mathrm{p}=0.626)$, perinatal morbidity $(7.2 \%$ vs. $17.2 \%$, $\mathrm{p}=0.011)$, prenatal mortality $(0 \%$ vs. $1.6 \% \mathrm{p}=0.391)$, congenital anomaly $(0.7 \%$ vs. $2.3 \%, \mathrm{p}=0.275)$ and IUD $(1.4 \%$ vs. $1.6 \% \mathrm{p}=0.934)$ were significantly different between euthyroid and dysfunction group, but in some other study $y^{5}$ there was found dissimilarity. The study of preterm delivery and thyroid dysfunction was documented an association but have not been proven casually related. It is therefore feasible that the increased incidence of preterm delivery is unrelated to the presence of thyroid disorders [14]. Preterm delivery in our subjects in both groups is similar but the cause is not properly evaluated as these subjects were also under the follow up of obstetricians and mode of delivery was significantly higher through Caesarean section. This study shows the frequencies of hypertensionpreeclampsia, spontaneous abortion, placental abruption, Caesarean section and $\mathrm{PPH}$ in different trimesters. Hypertension-preeclampsia as expected were more in the third $(6.1 \%)$ and second $(5.4 \%)$ trimester while spontaneous abortion was near equal in the first trimester $(4.7 \%)$ and second trimester $(4.0 \%)$. One large study revealed that incidence of maternal and fetal complications was higher in dysfunctional group than in euthyroid women but the difference was not significant which also may be due to early diagnosis and treatment ${ }^{9}$ that might explain our study results. Only preterm delivery was statistically different ( $\square 2-8.037$, p-0.045) in subgroups of thyroid dysfunction in our study. The study results show frequency for fetal complications in context to the antibody status. None of the fetal complications (antibody positive vs. antibody negative: preterm delivery $16.0 \%$ vs. $19.2 \%, \mathrm{p}=0.642$; LBW $12.0 \%$ Vs. $10,5 \%, \mathrm{p}=0.797$, perinatal morbidity $20.0 \%$ vs $15.4 \% \mathrm{p}=0.500$; perinatal mortality $2.0 \% \mathrm{v} 1.3 \%$ $\mathrm{p}=0.760$ : congenital anomaly $2.0 \%$ vs. $2.6 \%, \mathrm{p}=0.824$; IUD $3.9 \%$ vs $1.3 \%$ p-0.331) were statistically different between antibody positive and negative groups. Perinatal morbidity like birth asphyxia, jaundice is in higher frequencies in both groups and mostly seen in preterm delivery patients. The association of thyroid disease and adverse perinatal morbidity was not solely due to preterm delivery. ${ }^{15}$ Maternal and fetal complications in antibody positive subjects were not significantly higher in our study in any functional 
group. When birth weight of the babies was compared between euthyroid and dysfunction groups after stratification of the birth weight into three categories, the very LBW was found only in dysfunctional group. This may be due to the fact that all mothers were under treatment if found dysfunction in first trimester.

\section{Limitations OF THE STUdy}

This study was carried out at a tertiary level Hospital, subjects represented mostly urban and semiurban population, so true prevalence in our country as a whole might not have been reflected. Some participants were not in regular follow up schedule and 21 subjects were dropped and it may be due to some factors like lack of awareness, superstition and other antenatal visits in their nearby antenatal or private clinics. TT4 was not estimated which might have caused some masking of true function. The optimal method to assess serum FT4 during pregnancy is measurement of T4 in the dialysate or ultra-filtrate of serum samples employing on-line extraction/ liquid chromatography/ tandem mass spectrometry (LC/MS/MS), is not used in this study.

\section{CONCLUSION AND RECOMMENDATIONS}

Thyroid disorders in pregnancy are the second most common endocrine disorders in Bangladesh. Thyroid dysfunction may be attributable factor for maternal and fetal complications in pregnancy and during child birth, therefore mothers having thyroid dysfunction even in milder form should be under medical care throughout the pregnancy and until delivery. TSH and thyroid antibody status are important indicators for assesment over pregnancy outcome. Therefore, these should be checked during pregnancy and when appropriate TSH should be periodically followed throughout the gestation.

\section{REFERENCES}

1. Lata K, Dutta P, Sridhar S, Rohilla M, Srinivasan A, Prashad GR, Shah VN, Bhansali A. Thyroid autoimmunity and obstetric outcomes in women with recurrent miscarriage: a case-control study. Endocrine connections. 2013 Jun 1;2(2):118-24.

2. Hasanat MA, Rumi MA, Alam MN, Hasan KN, Salimullah M, Salam MA, Fariduddin M, Mahtab $\mathrm{H}$, Khan AA. Status of antithyroid antibodies in Bangladesh. Postgraduate medical journal. 2000 Jun 1;76(896):345-9.

3. Stagnaro-Green A, Abalovich M, Alexander E, Azizi F, Mestman J, Negro R, Nixon A, Pearce EN, Soldin OP, Sullivan S, Wiersinga W. Guidelines of the American Thyroid Association for the diagnosis and management of thyroid disease during pregnancy and postpartum. Thyroid. 2011 Oct 1;21(10):1081-125.
4. De Groot L, Abalovich M, Alexander EK, Amino N, Barbour L, Cobin RH, Eastman CJ, Lazarus JH, Luton D, Mandel SJ, Mestman J. Management of thyroid dysfunction during pregnancy and postpartum: an Endocrine Society clinical practice guideline. The Journal of Clinical Endocrinology \& Metabolism. 2012 Aug 1;97(8):2543-65.

5. Vanderpump MP, Tunbrldge WM, French J, Appleton D, Bates D, Clark F, Evans JG, Hasan DM, Rodgers H, Tunbridge F, Young ET. The incidence of thyroid disorders in the community: a twenty- year follow- up of the Whickham Survey. Clinical endocrinology. $1995 \mathrm{Jul} ; 43(1): 55-68$.

6. Akter F. Thyroid dysfunction and antithyroid antibodies in pregnant women attending tertiary care hospital (thesis). Department of Endocrinology, BSMMU. 2014.

7. Casey BM, Dashe JS, Wells CE, McIntire DD, Byrd W, Leveno KJ, Cunningham FG. Subclinical hypothyroidism and pregnancy outcomes. Obstetrics \& Gynecology. 2005 Feb 1;105(2):23945.

8. Begum SA, Shamsuddin L, Chowdhury SB, Fariduudin M, Chowdhury TS. Routine screening of thyroid function in early pregnancy. Diab Endocr Journal, 2004;32:31-35

9. Shah JM, Mehta MN, Viradia HB. Screening for thyroid dysfunction during pregnancy. Thyroid research and practice, 2013;10:65-67

10. Marx H, Amin P, Lazarus JH. Hyperthyroidism and pregnancy. Bmj. 2008 Mar 20;336(7645):6637.

11. Wang W, Teng W, Shan Z, Wang S, Li J, Zhu L, Zhou J, Mao J, Yu X, Li J, Chen Y. The prevalence of thyroid disorders during early pregnancy in China: the benefits of universal screening in the first trimester of pregnancy. European Journal of Endocrinology. 2011 Feb 1;164(2):263-8.

12. Galofre JC, Davies TF. Autoimmune thyroid disease in pregnancy: a review. Journal of Women's health. 2009 Nov 1;18(11):1847-56.

13. Glinoer D. The regulation of thyroid function in pregnancy: pathways of endocrine adaptation from physiology to pathology. Endocrine reviews. 1997 Jun 1;18(3):404-33.

14. Stagnaro-Green A. Maternal thyroid disease and preterm delivery. The Journal of Clinical Endocrinology \& Metabolism. 2009 Jan 1;94(1):21-5.

15. Männistö T, Mendola P, Reddy U, Laughon SK. Neonatal outcomes and birth weight in pregnancies complicated by maternal thyroid disease. American journal of epidemiology. 2013 Sep 1;178(5):731-40. 